\title{
Iron bioaccumulation in mycelium of Pleurotus ostreatus
}

\author{
Sandra M. Almeida ${ }^{1}$, Suzana H. Umeo ${ }^{1}$, Rafael C. Marcante ${ }^{1}$, Meire E. Yokota ${ }^{1}$, \\ Juliana S. Valle ${ }^{1}$, Douglas C. Dragunski ${ }^{2}$, Nelson B. Colauto ${ }^{1}$, Giani A. Linde ${ }^{1}$ \\ ${ }^{1}$ Laboratório de Biologia Molecular, Universidade Paranaense, Umuarama, PR, Brazil. \\ ${ }^{2}$ Laboratório de Química, Universidade Paranaense, Umuarama, PR, Brazil.
}

Submitted: June 22, 2013; Approved: June 6, 2014.

\begin{abstract}
Pleurotus ostreatus is able to bioaccumulate several metals in its cell structures; however, there are no reports on its capacity to bioaccumulate iron. The objective of this study was to evaluate cultivation variables to increase iron bioaccumulation in $P$. ostreatus mycelium. A full factorial design and a central composite design were utilized to evaluate the effect of the following variables: nitrogen and carbon sources, $\mathrm{pH}$ and iron concentration in the solid culture medium to produce iron bioaccumulated in mycelial biomass. The maximum production of $P$. ostreatus mycelial biomass was obtained with yeast extract at $2.96 \mathrm{~g}$ of nitrogen $\mathrm{L}^{-1}$ and glucose at $28.45 \mathrm{~g} \mathrm{~L}^{-1}$. The most important variable to bioaccumulation was the iron concentration in the cultivation medium. Iron concentration at $175 \mathrm{mg} \mathrm{L}^{-1}$ or higher in the culture medium strongly inhibits the mycelial growth. The highest iron concentration in the mycelium was $3500 \mathrm{mg} \mathrm{kg}^{-1}$ produced with iron addition of $300 \mathrm{mg} \mathrm{L}^{-1}$. The highest iron bioaccumulation in the mycelium was obtained in culture medium with $150 \mathrm{mg} \mathrm{L}^{-1}$ of iron. Iron bioaccumulation in $P$. ostreatus mycelium is a potential alternative to produce non-animal food sources of iron.
\end{abstract}

Key words: iron sulfate, functional food, hemoglobin, anemia.

\section{Introduction}

Pleurotus ostreatus (Jacq. ex Fr.) P. Kumm. (Pleurotaceae) is a basidiomycete with high nutritional (Muñoz et al., 2007), sensorial and functional value (Wasser, 2002). P. ostreatus can bioaccumulate metals in its structures (Philpott, 2006) using different acquisition strategies like the acidification of the culture medium and the production of chelating molecules (Haas, 2003).

Metal bioaccumulation for Pleurotus genus was described for several ions (Chiu et al., 1998; Kalac and Svoboda, 2000; Muñoz et al., 2007; Assunção et al., 2012; Silva et al., 2012). However, reports on iron bioaccumulation for this species have not been found. Iron is a broadly distributed natural transition metal (Hass, 2003). This compound may occupy multiple valences stably and, therefore, it is essential for different metabolic processes as ATP synthesis in the brain, maintenance of oxygen levels and enzyme co-factors (Dunn et al., 2007). Although it is abundant in nature, iron deficiency is reported as the most prevalent nutritional problem in the world, affecting more than two billion people and most of them are young children and women of reproductive age living in developing countries (WHO, 2001). Iron bioaccumulation by $P$. ostreatus could provide the development of functional foods enriched with iron.

P. ostreatus can be cultivated on a diversity of substrates, mainly, agricultural and agro industrial residues (Gern et al., 2008). However, these residues may have heavy metals and agricultural defensives. Mushrooms can bioaccumulate the contaminants from substrate and it has been a growing concern on mushroom production and consumption. The production of mycelial biomass could be an opportunity to iron enriched fungi. The mycelial production allows a greater control of the cultivation media avoiding bioaccumulation of contaminants (Mshandete and Mgonja, 2009). Furthermore, mushroom production takes several months to complete, and it is often difficult to control the product quality due to the use of different agricul- 
tural residues. Therefore the mycelium may be an economic and safe alternative for the production of foods, concentrating specific metals such as iron. Mycelium is widely used as an ingredient in many health foods and therapeutics because of its health benefits (Lee et al., 2004). Thus, the objective of this study was to evaluate cultivation variables that affect iron bioaccumulation in $P$. ostreatus mycelium.

\section{Material and Methods}

\section{Fungal strain}

$P$. ostreatus from the culture collection of the Paranaense University, cryopreserved at $-20{ }^{\circ} \mathrm{C}$ in wheat grains with saccharose (Mantovani et al., 2012), was transferred to agar extract malt medium $\left(39 \mathrm{~g} \mathrm{~L}^{-1}\right)$ and kept at $28^{\circ} \mathrm{C}$ in the dark to recover mycelial vigor. Mycelium, from the mycelial growth edge with homogenous branching and without sectioning, was used as inoculum. The strain was also deposited in the Fundação Oswaldo Cruz, Coleção de Micro-organismos de Referência em Vigilância Sanitária (FIOCRUZ/CMRVS), reference number Instituto Nacional de Controle de Qualidade em Saúde (INCQS) 40346 in the Coleção de Culturas de Fungos Filamentosos (CCFF), and registered in the World Data Centre for Microorganisms (WDCM) collection number 720 .

\section{Experimental design}

The influence of different variables on the mycelial growth and iron bioaccumulation was analyzed by the Full Factorial Design $2^{4}$ (FFD) (Neto et al., 2001). The variables and inferior $(-1)$ and superior $(+1)$ levels were: $\mathrm{pH}(4.5$ or 6.5 ), iron concentration ( 50 or $150 \mathrm{mg} \mathrm{L}^{-1}$ ) as $\mathrm{FeSO}_{4}$, carbon source (glucose or carboxymethyl cellulose; $20 \mathrm{~g} \mathrm{~L}^{-1}$ ) and nitrogen source (hydrolyzed casein or yeast extract; $1 \mathrm{~g}$ of nitrogen $\mathrm{L}^{-1}$ ). The total nitrogen content of hydrolyzed casein and yeast extract was determined by Kjeldahl method (Sáez-Plaza et al., 2013). Two other experiments, optimization of the mycelial biomass production and determination of the optimal range of bioaccumulated iron in the mycelium, were carried out from the results obtained in the FFD.

The optimization of the mycelial biomass production was done by a Central Composite Design $2^{2}$ (CCD) (Neto et $a l ., 2001)$. The studied variables and inferior ( $-\alpha$ and -1$)$, central (zero) and superior $(+1$ and $+\alpha)$ levels were: glucose concentrations $\left(3.2,10.0,20.0,30.0\right.$ or $\left.37.0 \mathrm{~g} \mathrm{~L}^{-1}\right)$ and the concentrations of yeast extract $(0.63,2.0,4.0,6.0$ or $7.36 \mathrm{~g}$ of nitrogen $\left.\mathrm{L}^{-1}\right)$. The best conditions for the mycelial biomass production, determined by CCD, were used to optimize the iron bioaccumulation in the mycelium. In this experiment only iron concentration was used as variable in the cultivation medium $(0,25,50,75,100,125,150,175$,
200,250 or $300 \mathrm{mg} \mathrm{L}^{-1}$ ). All experiments were done in five replications.

\section{Culture media}

The basis of culture medium consisted of $1.5 \mathrm{~g} \mathrm{~L}^{-1}$ $\mathrm{KH}_{2} \mathrm{PO}_{4}, 1 \mathrm{~g} \mathrm{~L}^{-1} \mathrm{NaCl}, 1.023 \mathrm{~g} \mathrm{~L}^{-1} \mathrm{MgSO}_{4} 7 \mathrm{H}_{2} \mathrm{O}, 0.01 \mathrm{~g} \mathrm{~L}^{-1}$ $\mathrm{ZnSO}_{4} 7 \mathrm{H}_{2} \mathrm{O}$ and $15.0 \mathrm{~g} \mathrm{~L}^{-1}$ agar (Pontecorvo et al., 1953). Culture media with addition of carbon source (glucose or carboxymethyl cellulose) or nitrogen source (hydrolyzed casein or yeast extract) were autoclaved at $121{ }^{\circ} \mathrm{C}$ for $20 \mathrm{~min}$. During the cooling, they received different volumes of previously filtered $(0.22 \mu \mathrm{m})$ aqueous solution of $\mathrm{FeSO}_{4} 7 \mathrm{H}_{2} \mathrm{O}\left(1000 \mathrm{mg} \mathrm{L}^{-1}\right)$. The $\mathrm{pH}$ was adjusted with $\mathrm{NaOH}$ or $\mathrm{HCl}(0.1 \mathrm{M})$ for both solutions that were previously autoclaved at $121^{\circ} \mathrm{C}$ for $20 \mathrm{~min}$. Culture media were homogenized and poured in Petri dishes (90 $\mathrm{mm}$ diameter). After total cooling a MAE disk ( $5 \mathrm{~mm}$ diameter) containing mycelium (inoculum) was placed at the center of the Petri dish in direct contact with the culture medium. All phases of the experiment were done under aseptic conditions. The mycelial growth was carried out at $28^{\circ} \mathrm{C}$ for 14 days.

\section{Production of mycelial biomass and iron bioaccumulation in the mycelium}

The Petri dishes containing grown mycelium were heated in a microwave oven for $10 \mathrm{~s}$. The mycelial biomass was removed from the medium surface and then washed three times in $200 \mathrm{~mL}$ of ultrapurified water at $80^{\circ} \mathrm{C}$. The water excess was removed by centrifugation at $1700 \mathrm{~g}$ for 15 min at $4{ }^{\circ} \mathrm{C}$. After that the mycelial biomass was dehydrated at $60{ }^{\circ} \mathrm{C}$ with air circulation until constant mass. The obtained biomass was mixed with 1:12 ( $\left.\mathrm{m} \mathrm{v}^{-1}\right)$ of $\mathrm{HNO}_{3}$ $(1.06 \mathrm{M})$ and kept at room temperature for $48 \mathrm{~h}$. The mixture was heated at $100{ }^{\circ} \mathrm{C}$ then mixed with $1: 6\left(\mathrm{~m} \mathrm{v}^{-1}\right)$ of $\mathrm{H}_{2} \mathrm{O}_{2}(0.88 \mathrm{M})$ until total solubilization. The final volume was adjusted to $50 \mathrm{~mL}$ with ultrapurified water and the iron concentration was determined by an atomic flame absorption spectrophotometer (Korn et al., 2008) (GBC, model 932 plus). The obtained results for both factorial experimental designs were evaluated by Pareto's analysis (Neto et al., 2001) using Statistica 6.0 software.

\section{Results}

The production of mycelial biomass by $P$. ostreatus was affected $(\mathrm{p} \leq 0.05)$ only by the carbon and nitrogen sources (Table 1). The negative effect of the carbon source $(-7.4080)$ indicates that the shift from the lower level (glucose) to the upper level (carboxymethyl cellulose) reduced biomass production in $7.4080 \mathrm{~g}$. Similarly the positive effect of the nitrogen source $(+3.0794)$ indicates that the shift from the lower level (hydrolyzed casein) to the upper level (yeast extract) provided higher $(\mathrm{p} \leq 0.05)$ mycelial biomass production of $3.0794 \mathrm{~g}$. Thus, the best carbon and nitrogen sources to produce biomass were glucose and yeast extract. 
Table 1 - Table 1. Effect of the variables in Pontecorvo solid culture medium by full factorial design $\left(2^{4}\right)$ on the responses of mycelial biomass production and iron bioaccumulation in the mycelium of Pleurotus ostreatus.

\begin{tabular}{lcc}
\hline Variables & Mycelial biomass $\left(\mathrm{g}_{\text {dry basis }}\right)$ & ${\text { Iron bioaccumulation in the mycelium }\left(\mathrm{mg} \mathrm{kg}{ }^{-1} \text { dry basis }\right)}$ \\
\hline Iron $\left(50\right.$ or $\left.150 \mathrm{mg} \mathrm{L}^{-1}\right)$ & +0.3228 & $+13.5327^{*}$ \\
Carbon (glucose or carboxymethyl cellulose) & $-7.4080^{*}$ & -0.5310 \\
Nitrogen (hydrolyzed casein or yeast extract) & $+3.0794^{*}$ & +2.9739 \\
$\mathrm{pH}(4.5$ or 6.5$)$ & +0.4656 & -1.0214 \\
\hline
\end{tabular}

*Significant effect $(\mathrm{p} \leq 0.05)$ on the response.

The addition of iron or the $\mathrm{pH}$ modification in the culture medium did not affect $(\mathrm{p} \leq 0.05)$ the production of mycelial biomass (within the evaluated levels). Thus, only glucose and yeast extract were used as variables for the next experimental phase of optimization of mycelial biomass production in a CCD due to the positive value of the $\mathrm{pH}$ effect. A $6.5 \mathrm{pH}$ value was chosen for biomass production optimization without iron addition.

Iron bioaccumulation in the mycelium was affected $(\mathrm{p} \leq 0.05)$ only by the iron concentration in the culture medium with positive effect $(+13.5327)$ (Table 1$)$. The effects indicates that the highest level $\left(150 \mathrm{mg} \mathrm{L}^{-1}\right.$ of iron in the culture medium) provided higher $(\mathrm{p} \leq 0.05)$ iron accumulation in the mycelial biomass. This makes evident that the iron concentration in the culture medium is essential for the bioaccumulation increase of this metal in the mycelial biomass (Table 1). Thus, the effect of the iron concentration on the production of mycelial biomass and bioaccumulation was analyzed in a broad iron concentration range, from zero to $300 \mathrm{mg} \mathrm{L}^{-1}$, in the culture medium.

\section{Production of mycelial biomass and iron bioaccumulation in the mycelium}

The second-order regression model was developed to predict the optimal point of the biomass production. The optimal range of yeast extract for the production of mycelial biomass was between 1.5 and $4.0 \mathrm{~g}$ of nitrogen $\mathrm{L}^{-1}$, and the optimal point was $2.96 \mathrm{~g}$ of nitrogen $\mathrm{L}^{-1}$. For glucose, the optimal range was from 25 to $35 \mathrm{~g} \mathrm{~L}^{-1}$, and the optimal point was $28.45 \mathrm{~g} \mathrm{~L}^{-1}$ (Figure 1). Knowing that $40 \%$ of glucose mass is carbon, the carbon-to-nitrogen ratio in the culture medium for the best range of mycelial production was from 3.5 to 6.6 , and the optimal point was 3.8 . Thus, the concentrations of the optimal point for the yeast extract and glucose were selected to optimize iron bioaccumulation in the mycelium (Figure 2).

Culture medium containing $28.45 \mathrm{~g} \mathrm{~L}^{-1}$ of glucose and $2.96 \mathrm{~g}$ of nitrogen $\mathrm{L}^{-1}$ from yeast extract was supplemented with different iron concentrations in order to increase biomass production and iron bioaccumulation. Iron bioaccumulation in the mycelium has increased with the increase of iron concentration in the culture medium (Figure 2). The concentration from zero to $150 \mathrm{mg} \mathrm{L}^{-1}$ of iron in

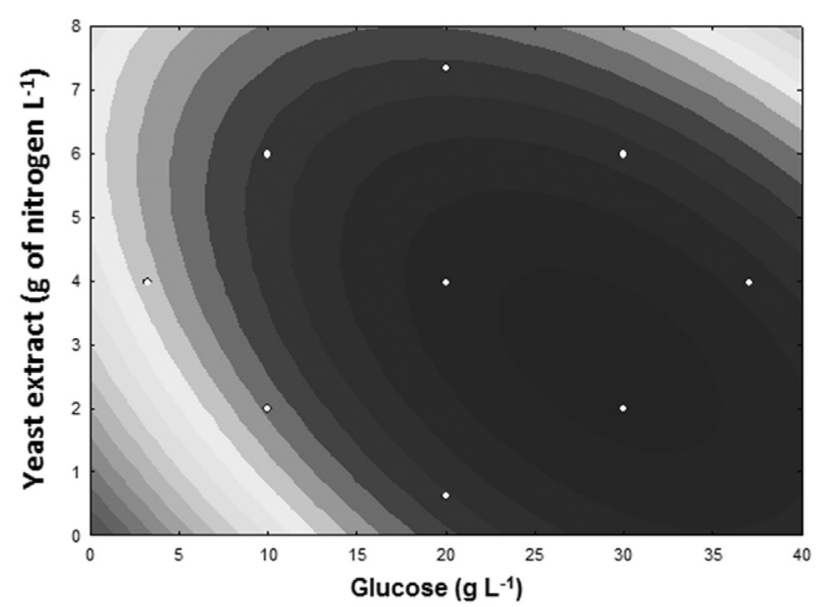

Figure 1 - Effect of yeast extract $\left(\mathrm{g}\right.$ of nitrogen $\left.\mathrm{L}^{-1}\right)$ and glucose $\left(\mathrm{g} \mathrm{L}^{-1}\right)$ on the production of Pleurotus ostreatus mycelial biomass ( $\left.g_{\text {dry basis }}\right)$. The darkest part of the figure indicates the combination of variables that promotes higher biomass production.

the culture medium did not affect the production of mycelial biomass (Figure 2), which is in agreement with FFD. However a strong inhibition of cellular growth started at $175 \mathrm{mg} \mathrm{L}^{-1}$, and total inhibition happened at $300 \mathrm{mg} \mathrm{L}^{-1}$. At $300 \mathrm{mg} \mathrm{L}^{-1}$, there was no production of mycelial biomass, therefore, it was not possible to evaluate the bioaccumulated concentration of iron in the mycelium. The close relationship between the iron bioaccumulation by the mycelium and the iron concentration in the culture medium are in accordance to the results obtained in FFD (Table 1) where only the iron concentration in the culture medium affected bioaccumulation of this metal in the mycelium.

Iron bioaccumulation in the mycelium occurred from 507 to $3616 \mathrm{mg} \mathrm{kg}^{-1}$ for a culture medium iron concentration ranging from 25 to $250 \mathrm{mg} \mathrm{L}^{-1}$ which represents a transference and accumulation of 20 and 14 times. The bioaccumulation yield (mycelial biomass multiplied by iron concentration) increased up to the concentration of $150 \mathrm{mg} \mathrm{L}^{-1}$ of iron in the culture medium (Figure 2). After this value, the yield was decreasing due to the reduction of the mycelial growth until complete inhibition at $300 \mathrm{mg} \mathrm{L}^{-1}$. 


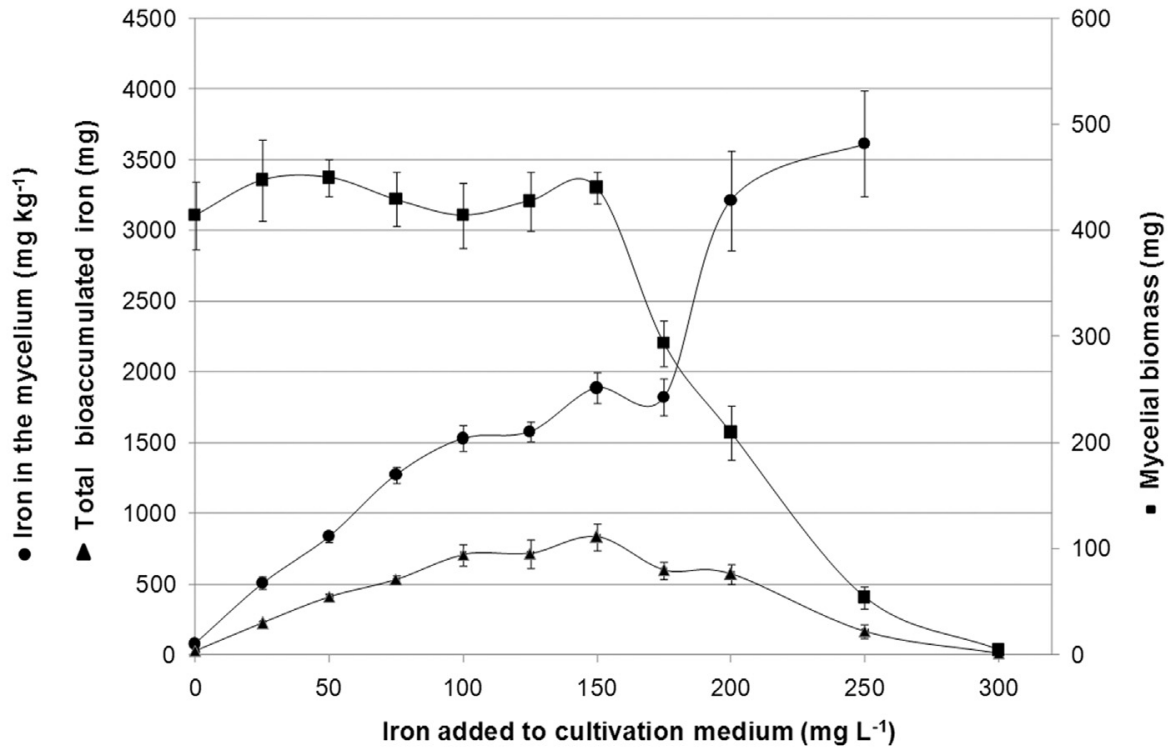

Figure 2 - Mycelial biomass production ( $\mathrm{mg}_{\text {dry basis }}$ ), iron bioaccumulation in the mycelium ( $\mathrm{mg} \mathrm{kg}^{-1}$ dry basis) and total bioaccumulated iron (mg) in mycelium of Pleurotus ostreatus grown in culture medium with different concentrations of iron (mg L $\left.{ }^{-1}\right)$.

\section{Discussion}

Glucose was the best carbon source for the production of mycelial biomass. Confortin et al. (2008), working with Pleurotus sajor-caju, and Gbolagade et al. (2006), with Pleurotus florida, obtained the highest biomass production using glucose rather than sucrose or fructose. The optimal concentration of glucose obtained in this study for the biomass production was $28.45 \mathrm{~g} \mathrm{~L}^{-1}$. This value is within the cited range in the literature for the mycelial production by Pleurotus genus, which is $8.18 \mathrm{~g} \mathrm{~L}^{-1}$ for P. sajor-caju (Confortin et al., 2008) and $40 \mathrm{~g} \mathrm{~L}^{-1}$ (Gern et al., 2008) and $60 \mathrm{~g} \mathrm{~L}^{-1}$ for $P$. ostreatus (Rosado et al., 2003). The best obtained results with glucose rather than carboxymethyl cellulose can be related to the cellular metabolic facility of this molecule whereas carboxymethyl cellulose needs the action of a group of enzymes to be hydrolyzed. Although glucose metabolization is apparently easier, for some microorganisms, metabolic repression can occur by the glucose presence (Ronne, 1995). However, the results found in our study indicate that it did not occur for P. ostreatus in the presence of up to $28.45 \mathrm{~g} \mathrm{~L}^{-1}$ glucose.

Yeast extract provided higher mycelial biomass production $(\mathrm{p} \leq 0.05)$ with optimal point at $2.96 \mathrm{~g}$ of nitrogen $\mathrm{L}^{-1}$. Gern et al. (2008) reported that the ideal concentration for $P$. ostreatus varies from 1.86 to $5.00 \mathrm{~g}$ nitrogen $\mathrm{L}^{-1}$. This positive effect of the yeast extract in the basidiomycete production is also reported for Grifola frondosa and Auricularia polytricha (Lee et al., 2004) and for P. sajorcaju (Confortin et al., 2008). The appropriateness of this nitrogen source for the production of mycelial biomass in basidiomycetes, especially $P$. ostreatus, can be associated to its microbial origin with distribution of aminoacids closer to fungal composition. Moreover, hydrolyzed casein, besides being a nitrogen source of animal origin, undergoes denaturation during sterilization with loss of solubility and smaller accessibility to the enzymatic action of the fungus.

The highest production of mycelial biomass in our study was obtained in the culture medium with carbonto-nitrogen ratio of 3.8. This result is closer to the one reported by Fasidi and Oiorunmaiye (1994) that determined the optimal carbon-to-nitrogen ratio as 4.0 for the production of mycelial biomass of Pleurotus tuber-region in submerged cultivation. This indicates that $P$. ostreatus mycelium is tolerant to high concentrations of nitrogen and low carbon-to-nitrogen ratio in culture media.

Iron concentration in the culture medium negatively affected the mycelial growth at $175 \mathrm{mg} \mathrm{L}^{-1}$ and caused complete growth inhibition at $300 \mathrm{mg} \mathrm{L}^{-1}$. Dunn et al. (2007) reported that iron excess causes cell toxicity due to the high reactivity of ions that trigger oxidative stress. The increase of iron concentration in the culture medium also causes the induction of manoprotein synthesis (Protchenko et al., 2001). These proteins keep at the cell membrane the iron from siderophores, peptic molecules specialized in iron transport (Haas, 2003). Moreover, all these metabolic routes of iron absorption depend on the action of metal reductases to transform $\mathrm{Fe}^{+3}$ to $\mathrm{Fe}^{+2}$. Therefore, besides the oxidative stress, metabolism is directed towards the synthesis of iron chelating compounds as a defense strategy of the fungus and not to the cell growth.

The increase of iron concentration in the culture medium caused the increase of iron bioaccumulation in $P$. ostreatus mycelium, and the highest bioaccumulation yield occurred with the addition of $150 \mathrm{mg} \mathrm{L}^{-1}$ of iron. According 
to Kosman (2003), fungi depend on iron oxidation to increase bioavailability as well as to reduce the iron cytotoxicity to keep intracellular homeostasis. The versatility and redundancy that basidiomycetes have to bioaccumulate iron are reported (Haas, 2003). Therefore, basidiomycetes use a variety of iron absorption systems such as the ferric iron system that starts by reducing $\mathrm{Fe}^{3+}$ to $\mathrm{Fe}^{2+}$ by the iron reductase action. It is likely that the fungus has used this iron absorption system as a defense mechanism to free radicals produced in the oxidative processes mediated by iron. For instance ferric uptake regulation protein acts as a siderophore synthesis repressor and on the expression of iron superoxide dismutase enzyme (Kosman, 2003).

In our experiment, the mycelium bioaccumulated up to 20 times the iron concentration available in the culture medium. Basidiomycete mycelium can bioaccumulate copper and zinc at, 449 and 163 times the medium basal content for Agaricus blazei, respectively (Rabinovich et al., 2007) and 2 and 11 times for Grifola frondosa (Figlas et al., 2010). For P. ostreatus basidiocarps, the concentration of mercury was from 65 to 140 times (Bressa et al., 1988). Several factors affect the bioaccumulation capacity of basidiomycetes like strain, cultivation method, fungus development phase, oxidative state of the mineral, among others (Baldrian, 2003). Nevertheless, P. ostreatus has been the most studied basidiomycete for heavy metal bioaccumulation and nutritional interest due to its growth strength even in highly contaminated substrates.

Mushrooms can bioaccumulate contaminants from natural substrate and it has been a growing concern in mushroom production. For $P$. ostreatus basidiocarp the concentrations of heavy metals found, in dry basis, are $1.38 \mathrm{mg} \mathrm{kg}^{-1} \mathrm{Cd}$ (Favero et al., 1990) to $3.0 \mathrm{mg} \mathrm{kg}^{-1}$ (Isildak et al., 2004); $0.02 \mathrm{mg} \mathrm{kg}^{-1} \mathrm{Hg}$ (Bressa et al., 1988); 0.5 to $1.0 \mathrm{mg} \mathrm{kg}^{-1} \mathrm{~Pb}$ (García et al., 2009); $1.3 \mathrm{mg} \mathrm{kg}^{-1} \mathrm{Cr} ; 0.4 \mathrm{mg}$ $\mathrm{kg}^{-1} \mathrm{Ni}$ and $8.5 \mathrm{mg} \mathrm{kg}^{-1} \mathrm{Cu}$ (Isildak et al., 2004). Therefore, contamination of mushrooms with heavy metals represent a low risk to the public health, in general, but could be a serious problem for those with weakened and immunosuppressed health.

The production of iron enriched mycelial biomass could be an opportunity to use it as a functional food because of its health benefits (Lee et al., 2004) avoiding the heavy metal accumulation. In our work the bioaccumulated iron concentrations in the mycelium were up to $3500 \mathrm{mg}$ $\mathrm{kg}^{-1}$. Basidiocarps of $P$. ostreatus naturaly have iron concentrations, in dry basis, ranging from 48 to $280 \mathrm{mg} \mathrm{kg}^{-1}$ (Vetter, 1994; Tüzen et al., 1998; Demirbas, 2001; Isildak et al., 2004; Gençcelep et al., 2009; Patil et al., 2010). The mycelium of $P$. ostreatus bioaccumulated at least five times more iron than basidiocarp. Thus, iron bioaccumulated mycelium could be an alternative food concentrated with iron of a non-animal source. Future experiments could compare mycelium and basidiocarp bioaccumulation capacity and bioavaibility in vitro and in vivo; include other other func- tional basidiomycetes; evaluate other biological activities of enriched mycelium and basidiocarp as an alternative source of iron.

\section{Acknowledgments}

The authors thank the Paranaense University, the Postgraduate Program in Biotechnology Applied to Agriculture of the Paranaense University, Fundação Araucária, Coordenação de Aperfeiçoamento de Pessoal de Nível Superior (CAPES) and Conselho Nacional de Desenvolvimento Cientifico e Tecnológico (CNPq) for the financial support and the fellowship.

\section{References}

Assunção LS, Luz JRM, Silva MCS et al. (2012) Enrichment of mushrooms: an interesting strategy for the acquisition of lithium. Food Chem 134:1123-1127.

Baldrian P (2003) Interactions of heavy metals with white-rot fungi. Enzyme Microb Technol 32:78-91.

Bressa G, Cima L, Costa P (1988) Bioaccumulation of Hg in the mushroom Pleurotus ostreatus. Ecotox Environ Safe 16:85-89.

Chiu SW, Chan YH, Law SC et al. (1998) Cadmium and manganese in contrast to calcium reduce yield and nutritional values of the edible mushroom Pleurotus pulmonarius. Mycologia 102:449-457.

Confortin FG, Marchetto R, Bettin F et al. (2008) Production of Pleurotus sajor-caju strain PS-2001 biomass in submerged culture. J Ind Microbiol Biotechnol 35:1149-1155.

Demirbas A (2001) Heavy metal bioaccumulation by mushrooms from artificially fortified soils. Food Chem 74:293-301.

Dunn LL, Rahmanto YS, Richardson DR (2007) Iron uptake and metabolism in the new millennium. Trends Cell Biol 17:93100.

Fasidi IO, Oiorunmaiye KS (1994) Studies on the requirements for vegetative growth of Pleurotus tuber-region (Fr.) Singer, a Nigerian mushroom. Food Chem 50:397-401.

Favero N, Bressa G, Costa P (1990) Response of Pleurotus ostreatus to cadmium exposure. Ecotox Environ Safe 20:16.

Figlas D, Oddera M, Curvetto N (2010) Bioaccumulation and bioavailability of copper and zinc on mineral-enriched mycelium of Grifola frondosa. J Med Food 13:469-475.

García MA, Alonso J, Melgar MJ (2009) Lead in edible mushrooms: levels and bioaccumulation factors. J Hazard Mater 167:777-783.

Gbolagade J, Sobowale A, Adejoye D (2006) Optimization of sub-merged culture conditions for biomass production in Pleurotus florida (mont.) Singer, a Nigerian edible fungus. Afr J Biotechnol 5:1464-1469.

Gençcelep H, Uzun Y, Tunçtürk Y et al. (2009) Determination of mineral contents of wild-grown edible mushrooms. Food Chem 113:1033-1036.

Gern RMM, Wisbeck E, Rampinelli JR et al. (2008) Alternative medium for production of Pleurotus ostreatus biomass and potential antitumor polysaccharides. Bioresour Technol 99:76-82. 
Haas H (2003) Molecular genetics of fungal siderophore biosynthesis and uptake: the role of siderophores in iron uptake and storage. Appl Microbiol Biotechnol 62:316-330.

Isildak Ö, Turkekul I, Elmastas M et al. (2004). Analysis of heavy metals in some wild-grown edible mushrooms from the middle black sea region Turkey. Food Chem 86:547-552.

Kalac P, Svoboda L (2000) A review of trace element concentrations in edible mushrooms. Food Chem 69:273-281.

Korn MGA, Morte ESB, Santos DCMB et al. (2008) Sample preparation for the determination of metals in food samples using spectroanalytical methods - A review. Appl Spectrosc Rev 43:67-92.

Kosman DJ (2003) Molecular mechanisms of iron uptake in fungi. Mol Microbiol 47:1185-1197.

Lee BC, Bae JT, Pyo HB et al. (2004) Submerged culture conditions for the production of mycelial biomass and exopolysaccharides by the edible basidiomycete Grifola frondosa Enzyme Microb Technol 35:369-376.

Mantovani TRD, Tanaka HS, Umeo SH et al. (2012) Cryopreservation at -20 and $-70{ }^{\circ} \mathrm{C}$ of Pleurotus ostreatus on grains. Indian J Microbiol 52:484-488.

Mshandete AM, Mgonja JR (2009) Submerged liquid fermentation of some Tanzanian basidiomycetes for the production of mycelial biomass, exopolysaccharides and mycelium protein using wastes peels media. J Agric Biol 4:1-13.

Muñoz AHS, Wrobel K, Corona JFG et al. (2007) The protective effect of selenium inorganic forms against cadmium and silver toxicity in mycelia of Pleurotus ostreatus. Mycol Res 111:626-632.

Neto BB, Scarminio IS, Bruns RE (2001) Planejamento e Otimização de Experimentos. 2 edition. Unicamp, Campinas.

Patil SS, Ahmed SA, Telang SM (2010) The nutritional value of Pleurotus ostreatus (Jacq.: Fr.) Kumm cultivated on different lignocellulosic agro-wastes. Innov Rom Food Biotechnol 7:66-76.

Philpott CC (2006) Iron uptake in fungi: a system for every source. Biochim Biophys Acta 1763:636-645.

Pontecorvo G, Roper JA, Hemmons LM et al. (1953) The genetics of Aspergillus nidulans. Adv Genet 5:141-238.
Protchenko O, Ferea T, Rashford J et al. (2001) Three cell wall mannoproteins facilitate the uptake of iron in Saccharomyces cerevisiae. J Biol Chem 276:49244-49250.

Rabinovich M, Figlas D, Delmastro S et al. (2007) Copper- and zinc-enriched mycelium of Agaricus blazei Murrill: bioaccumulation and bioavailability. J Med Food 10:175-183.

Ronne H (1995) Glucose repression in fungi. Trends Genet 11:12-17.

Rosado FR, Germano S, Carbonero ER et al. (2003) Biomass and exopolysaccharide production in submerged cultures of Pleurotus ostreatoroseus Sing. and Pleurotus ostreatus "florida" (Jack.: Fr.) Kummer. J Basic Microbiol 43:230237.

Sáez-Plaza P, Navas MJ, Wybraniec S et al. (2013) An overview of the Kjeldahl method of nitrogen determination. Part III. Sample preparation, working scale, instrumental finish and quality control. Crit Rev Anal Chem 43:224-272.

Silva MCS, Naozuka J, Luz JMR et al. (2012) Enrichment of Pleurotus ostreatus mushrooms with selenium in coffee husks. Food Chem 131:558-563.

Tüzen M, Ozdemiti M, Demirbas A (1998) Study of heavy metals in some cultivated and uncultivated mushrooms of Turkish origin. Food Chem 63:247-251.

Vetter J (1994) Mineral elements in the important cultivated mushrooms Agaricus bisporus and Pleurotus ostreatus. Food Chem 50:277-279.

Wasser SP (2002) Medicinal mushrooms as a source of antitumor and immunomodulating polysaccharides. Appl Microbiol Biotechnol 60:258-274.

World Health Organization (2001) Iron deficiency anaemia: assessment, prevention and control. A guide for programme managers. World Health Organization, Geneva. Available at: http://whqlibdoc.who.int/hq/2001/WHO_NHD_01.3.pdf. Accessed 6 May 2013.

Associate Editor: Rosane Freitas Schwan

All the content of the journal, except where otherwise noted, is licensed under a Creative Commons License CC BY-NC. 